\title{
Synthesis, Characterization and Application of ZS/HMS Catalyst in the Esterification of Gossypol
}

\author{
Shihong Dong, Mingyuan Zhu* ${ }^{*}$ Bin Dai* \\ Key Laboratory for Green Processing of Chemical Engineering of Xinjiang Bingtuan, \\ School of Chemistry and Chemical Engineering, Shihezi University, Shihezi, China \\ Email: ${ }^{*}$ zhuminyuan@shzu.edu.cn, ${ }^{*}$ db_tea@shzu.edu.cn
}

Received November 3, 2011; revised December 8, 2011; accepted December 17, 2011

\begin{abstract}
A solid acid catalyst of zirconium sulfate (ZS) on a pure hexagonal mesoporous silica (HMS) sieve was prepared and characterized by small angle $\mathrm{X}$-ray diffraction, $\mathrm{NH}_{3}$-temperature programmed desorption, and thermogravimetric analysis. The obtained ZS/HMS catalyst displayed a typical mesoporous structure, ZS was well dispersed on the HMS support, and the acidity increased with the amount of ZS loading. Gossypol was extracted from cottonseed cake with acetone as solvent, and then the gossypol solution was esterified with ZS/HMS as catalyst to yield products of acetic acid gossypol. Under the optimal conditions, the conversion efficiency of gossypol was as high as $96.7 \%$.
\end{abstract}

Keywords: Gossypol; Zirconium Sulphate; Hexagonal Mesoporous Silica; Esterification

\section{Introduction}

Gossypol is a polyphenolic compound derived from the yellow pigment glands of cotton plants that plays an important role in pest resistance [1,2]. Acetylated gossypol is the esterification product of gossypol and acetic acid. Acetylated gossypol has been studied in a wide range of biological and medicinal fields due to its purported antitumor and antifertility activities [3-5]. Gossypol is usually extracted from cottonseed kernels using aniline as intermediates $[5,6]$. The toxic residue in the cottonseed cake is harmful to both humans and animals. Therefore, development of a non-toxic extraction method for acetylated gossypol from cottonseed cake is of great importance.

Solid acid catalysts are widely used in esterification reactions because of their low acute toxicity. Furthermore, there is no evidence of carcinogenicity to humans. Several recent studies reported that zirconium sulfate (ZS) showed high activity and selectivity as a solid acid catalyst for the esterification of fatty acids [7]; however, ZS is easily soluble in water and difficult to remove from the reaction mixture. To circumvent this problem, many recent studies have investigated the synthesis of immobilized ZS supported on various supports such as activated carbon [8], $\gamma$-alumina [9], silica [10], carbon nanotubes [11], or MCM-41 [12] as a solid catalysts.

Acetylated gossypol is the esterification product of gossypol and solid acid catalyst may be able to enhance the conversion ratio of this reaction. In this paper, we

"Corresponding author. describe the preparation of immobilized ZS on hexagonal mesoporous silica (HMS) sieve. The ZS/HMS was characterized and applied as a solid acid catalyst for the esterification of gossypol. The loading of ZS on HMS, the amount of catalyst, the reaction time, and reaction temperature were investigated to optimize the reaction conditions for gossypol esterification.

\section{Experimental}

\subsection{Catalyst Preparation}

Pure siliceous HMS material was synthesized according to a procedure described previously [13]. Briefly, dodecylamine (DDA, $4.9 \mathrm{mmol}$ ) was dissolved in $5 \mathrm{~mL}$ of ethanol, and $45 \mathrm{~mL}$ of distilled $\mathrm{H}_{2} \mathrm{O}$ was then added to afford a 90:10 (V/V) $\mathrm{H}_{2} \mathrm{O} / \mathrm{EtOH}$ solution of the surfacetant. At room temperature, tetraethyl orthosilicate (TEOS $19.6 \mathrm{mmol}$ ) was added to the solution to yield a reaction mixture. Into this reaction mixture, we added $7 \mathrm{~mL}$ ethanol during the mixing process to compensate for the volatilization. The reaction flask was sealed with cling film and shaken at $220 \mathrm{rpm}$ in a heated water bath at room temperature for $20 \mathrm{~h}$. The reaction product was then filtered, washed, and dried at room temperature for $24 \mathrm{~h}$. The obtained samples were calcined in a muffle furnace at about $600^{\circ} \mathrm{C}$ for $4 \mathrm{~h}$.

The ZS/HMS materials were synthesized following procedures similar to those of Joon and his co-works [14]. The ZS-impregnated HMS catalyst was prepared by first dispersing the HMS in a water solution and then adding 
ZS. The mixture was stirred overnight and then dried at $120^{\circ} \mathrm{C}$ for $10 \mathrm{~h}$. The samples obtained after drying were denoted $\mathrm{X} \% \mathrm{ZS} / \mathrm{HMS}$ ( $\mathrm{X} \%$ refer to loading of the $\mathrm{ZS}$ ). Before use in the reaction, the ZS/HMS catalyst was stored in desiccators.

\subsection{Characterization}

The powder X-ray diffraction (XRD) data was collected on a Brunker D8 Advance X-ray diffractometer using $\mathrm{Cu}-\mathrm{K} \alpha$ irradiation $(\lambda=1.5406 \AA)$ as source at $40 \mathrm{kV}$ and $40 \mathrm{~mA}$. The samples were recorded from 1 to $20^{\circ}(2 \theta)$ with a step scan of $0.01 \%$.

Brunauer-Emmett-Teller (BET) surface area analysis was performed from the nitrogen adsorption isotherms at 77 K using a Micromeritics Model ASAP 2020 instrument. All samples were degassed at $110^{\circ} \mathrm{C}$ under vacuum for $6 \mathrm{~h}$. Average pore diameter (d) and pore volume were calculated based on the Barret-Joyner-Halenda (BJH) method.

The $\mathrm{NH}_{3}$-temperature programmed desorption $\left(\mathrm{NH}_{3}\right.$ TPD) data were collected using a ChemBet 3000 analyzer. About $200 \mathrm{mg}$ samples were activated under flowing heat $\left(500^{\circ} \mathrm{C}\right)$ for $2 \mathrm{~h}$, and cooled to $120^{\circ} \mathrm{C}$ under continuous evacuation. The sample was equilibrated with gaseous $\mathrm{NH}_{3}$ at $0.04 \mathrm{kPa}$ and the temperature increased by $10^{\circ} \mathrm{C} / \mathrm{min}$ under flowing heat $20 \mathrm{~cm}^{3} / \mathrm{min}$.

Thermogravimetric analysis (TGA) was performed on a Netzsch STA-449F3 (Jupiter OR, Germany) analyzer under an oxygen atmosphere. Heating rates were typically $10^{\circ} \mathrm{C} / \mathrm{min}$ under an oxygen atmosphere. The gas flow through the system was $20 \mathrm{~mL} / \mathrm{min}$.

\subsection{Extraction of Gossypol}

A sample of cottonseed cake raw material was weighed. After grinding, cottonseed cake was put into a grind port flask. An appropriate amount of acetone was added to the flask. The cottonseed cake extracting solution was removed from the residue by vacuum filtration. The remaining residue was washed three times with $50 \mathrm{~mL}$ of distilled water to remove residual solvents. The liquid product was filtered through a $0.45 \mu \mathrm{m}$ organic membrane and 20 $\mu 1$ of the filtrate was analyzed by high performance liquid chromatography. The chromatographic conditions, an $\mathrm{C}_{18}$ reversed-phase column was used. The particle size was 5 $\mu \mathrm{m}$, and the column dimensions were $4.6 \mathrm{~mm} \times 150 \mathrm{~mm}$, the mobile phase were methanol and $2 \%$ phosphoric acid solution (90:10), the column temperature was $40^{\circ} \mathrm{C}$, the flow rate was $1 \mathrm{~mL} / \mathrm{min}$ and the samples were detected by Waters a $2487 \mathrm{UV}$ detector at $235 \mathrm{~nm}$. The extraction yield of gossypol from cottonseed cake was calculated by the following formula:

$$
\mathrm{R}(\%)=\left(\mathrm{W}_{1} / \mathrm{W}_{2}\right) \times 100 \%
$$

The formula: R - extraction yield of gossypol; $\mathrm{W}_{1}$ - extracting amount of gossypol;

$\mathrm{W}_{2}$ - the total content of gossypol in cottonseed cake.

\subsection{Esterification of Gossypol with Acetic Acid}

Esterification was performed at atmospheric pressure in a grinding glass bottle. A typical esterification reaction consists of acetic acid $(1 \mathrm{~mL}), 0.6 \mathrm{mg} / \mathrm{mL}$ of gossypol (5 $\mathrm{mL})$, distilled water $(3.2 \mathrm{~mL})$, and fresh ZS/HMS solid acid catalyst $(0.1 \mathrm{~g})$. After acetic acid and gossypol were mixed and stirred for 15 minutes, distilled water was added drop by drop. The reaction mixture was kept on stir for esterification. At the beginning of the reaction, the catalyst was handed by ultrasonic dispersion. Speed of agitation had only a small effect on the reaction rate. All subsequent experiments were conducted at a stirrer speed of $200 \mathrm{rpm}$ to ensure that there was no external mass transfer resistance. After standing for 10 minutes, the produced acetic acid gossypol was precipitated due to its low solubility in water, and then the upper supernatant was taken using HPLC to detect the remaining amount of gossypol and computed the conversion of gossypol. The yellow precipitation was dissolved in acetone with a certain amount. After stirring for 10 minutes, the sample was filtered in order to obtain a pure gossypol acetic acid.

\section{Results and Discussion}

Figure 1 shows the typical XRD pattern for the ZS/HMS reaction product with different $\mathrm{ZS}$ loading. The patterns all contain an intense diffraction peak $2 \theta=2.3^{\circ}$ corresponding to the diffraction of (100) plane, indicating that these samples had the typical characteristic peaks of a mesoporous molecular sieve in agreement with previous reports [15].

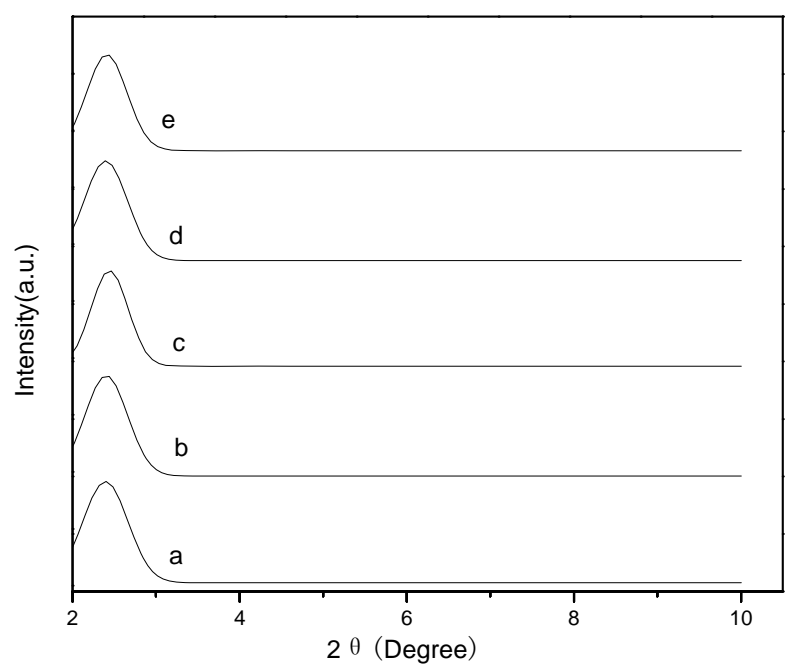

Figure 1. XRD patterns of ZS/HMS material for different ZS/HMS ratios: a: HMS; b: $30 \% \mathrm{ZS} / \mathrm{HMS}$; c: $40 \% \mathrm{ZS} /$ HMS; d: $\mathbf{5 0 \%}$ ZS/HMS; and e: $60 \%$ ZS/HMS. 
The textural properties of samples were examined by surface area and pore size distribution (Table 1). The average surface area of the HMS was $637 \mathrm{~m}^{2} / \mathrm{g}$. Surface area and pore volume decreased with increasing ZS loads, while the average pore size of ZS/HMS expanded from 3.2 to $4.1 \mathrm{~nm}$ with increasing ZS. At higher ZS loads, ZS particles will enter into the surface the microporous structure and block superficial pores, reducing surface area and surface pore volume. The pore volume reduced from 0.60 $\mathrm{cm}^{3} / \mathrm{g}$ to $0.20 \mathrm{~cm}^{3} / \mathrm{g}$. Pore size distributions are shown in Figure 2 and measured by N2 adsorption technique. The pore sizes of catalyst decrease with increment of ZS loading. As these surface microporous are blocked, the remaining pores of the support must be larger, so the average pore size underestimates the average pore diameters within the ZS/HMS solid acid catalyst.

The nitrogen adsorption isotherms for HMS and ZS/ HMS samples with different ZS loading are shown in Figure 3. All samples exhibited the shape of II isotherms according to the IUPAC classification for nitrogen adsorption-desorption isotherms. The adsorption and desorption branches were not parallel and hysteresis loops emerge between 0.9 and 1 . The hysteresis loops of ZS/ HMS were similar to those of parent of HMS, indicating that ZS had good loading dispersion, consistent with the $\mathrm{XRD}$ and results.

Table 1. The structure of various ZS/HMS samples.

\begin{tabular}{cccc}
\hline Sample & $\mathrm{S}_{\mathrm{BET}}\left(\mathrm{m}^{2} / \mathrm{g}\right)$ & $\mathrm{d}(\mathrm{nm})$ & Pore volume $\left(\mathrm{cm}^{3} / \mathrm{g}\right)$ \\
\hline HMS & 637 & 3.2 & 0.60 \\
$20 \%$ ZS/HMS & 571 & 3.4 & 0.48 \\
$30 \%$ ZS/HMS & 315 & 3.7 & 0.29 \\
$40 \%$ ZS/HMS & 253 & 4.0 & 0.26 \\
$50 \%$ ZS/HMS & 213 & 4.1 & 0.22 \\
$60 \%$ ZS/HMS & 193 & 4.1 & 0.20 \\
\hline
\end{tabular}

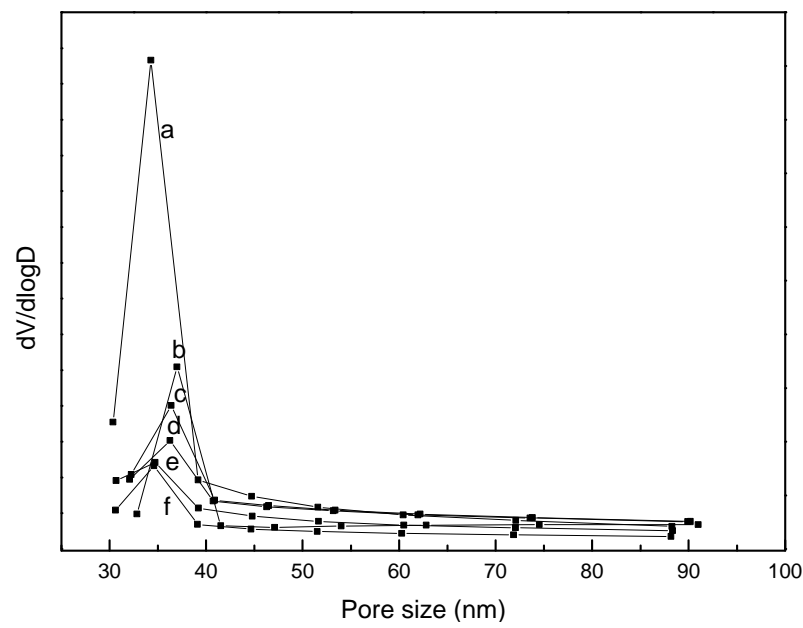

Figure 2. Pore size distributions for a: HMS; b: $20 \% \mathrm{ZS} /$ HMS; c: $\mathbf{3 0} \%$ ZS/HMS; d: $\mathbf{4 0 \%}$ ZS/HMS; e: $\mathbf{5 0 \% ~ Z S / H M S ; ~}$ and f: $60 \%$ HMS.

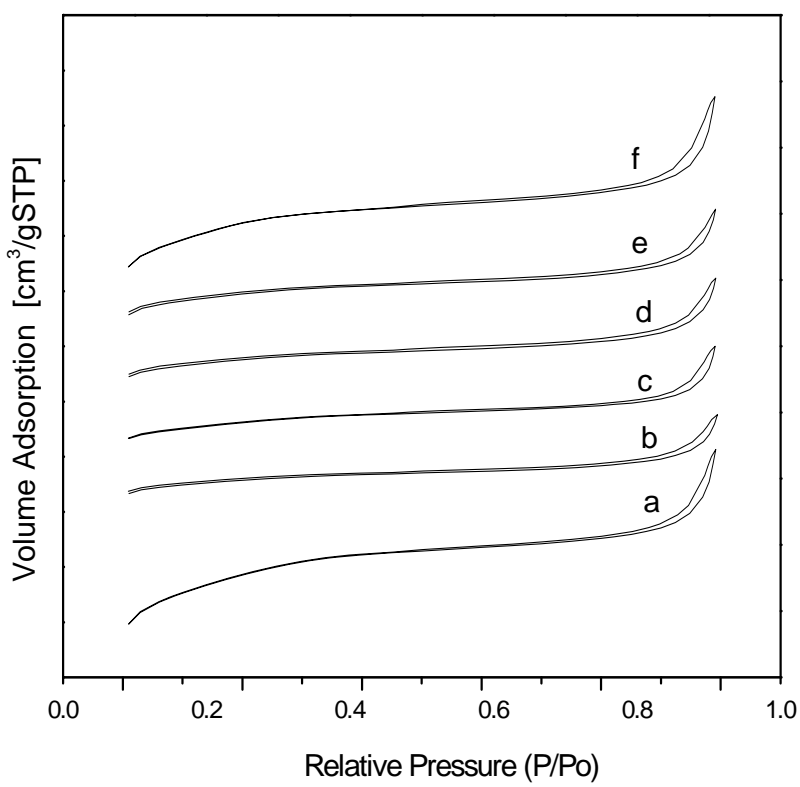

Figure 3. Nitrogen adsorption isotherms for a: HMS; b: 20\% ZS/HMS; c: $\mathbf{3 0 \% ~ Z S / H M S ; ~ d : ~} \mathbf{4 0 \% ~ Z S / H M S ; ~ e : ~} \mathbf{5 0 \%}$ ZS/HMS, and f: $\mathbf{6 0 \%}$ HMS.

There are many methods for acidity measurements [16, 17]. Ammonia TPD is widely used to determine the acidity of solid acid. The $\mathrm{NH}_{3}$-TPD profiles of HMS and ZS/HMS are shown in Figure 4. Gannapati et al. [18] reported that desorption temperature could be divided into three categories: 1) intermediate or medium $\left(100^{\circ} \mathrm{C}\right.$ $\left.200^{\circ} \mathrm{C}\right)$; 2) strong $\left(200^{\circ} \mathrm{C}-400^{\circ} \mathrm{C}\right)$; 3) very strong acid $\left(>400^{\circ} \mathrm{C}\right)$. The HMS exhibited one peak at $125^{\circ} \mathrm{C}$, reflecting the physical adsorption of $\mathrm{NH}_{3}$ on the HMS surface. When zirconium was loaded onto the HMS, peaks of different intensities (heights) at $242^{\circ} \mathrm{C}$ will appear that indicate strong acid strength. As the zirconium content increased, the peak intensity also increased. The peak height was equivalent at $50 \%$ zirconium and $60 \%$ zirconium loads, indicating that these two load levels deposited equal amounts of ZS on the HMS.

Thermogravimetric analysis was conducted under atmospheric conditions to test the thermal stability of bulk ZS and HMS-supported ZS. The thermograms of HMS and $\mathrm{ZS} / \mathrm{HMS}$ materials with various $\mathrm{ZS}$ loadings are shown in Figure 5. The first change in TGA curve between room temperature and $100^{\circ} \mathrm{C}$ is ascribed to removal of physiccally adsorbed and structural water. At higher temperatures, TGA curves yield the decomposition pattern of ZS/HMS. The profiles indicated that the unmodified HMS showed little loss; however, TGA curves of ZS/HMS revealed degradation between $650^{\circ} \mathrm{C}$ and $750^{\circ} \mathrm{C}$, reflecting breakdown of ZS groups on the silica surface, in agreement with earlier reports [19].

The orthogonal test results for optimal extraction of gossypol from cottonseed cake are listed in Tables $\mathbf{2}$ and 


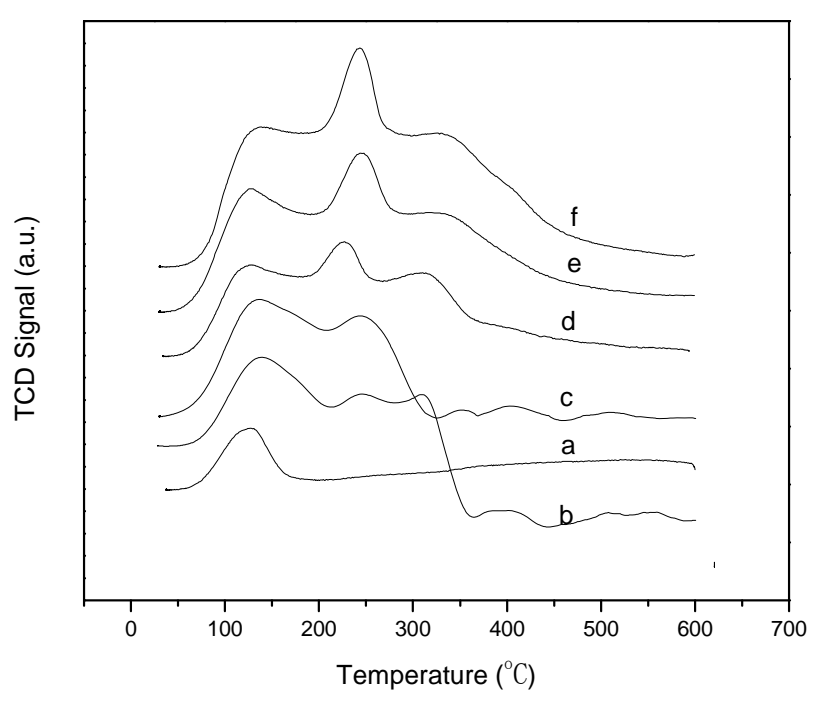

Figure 4. $\mathrm{NH}_{3}$-TPD curves for a: HMS; b: $20 \% \mathrm{ZS} / \mathrm{HMS}$; c: $30 \% \mathrm{ZS} / \mathrm{HMS}$; d: $\mathbf{4 0} \% \mathrm{ZS} / \mathrm{HMS}$; e: $\mathbf{5 0 \%} \mathrm{ZS} / \mathrm{HMS}$; and $\mathrm{f}$ : $60 \%$ HMS.

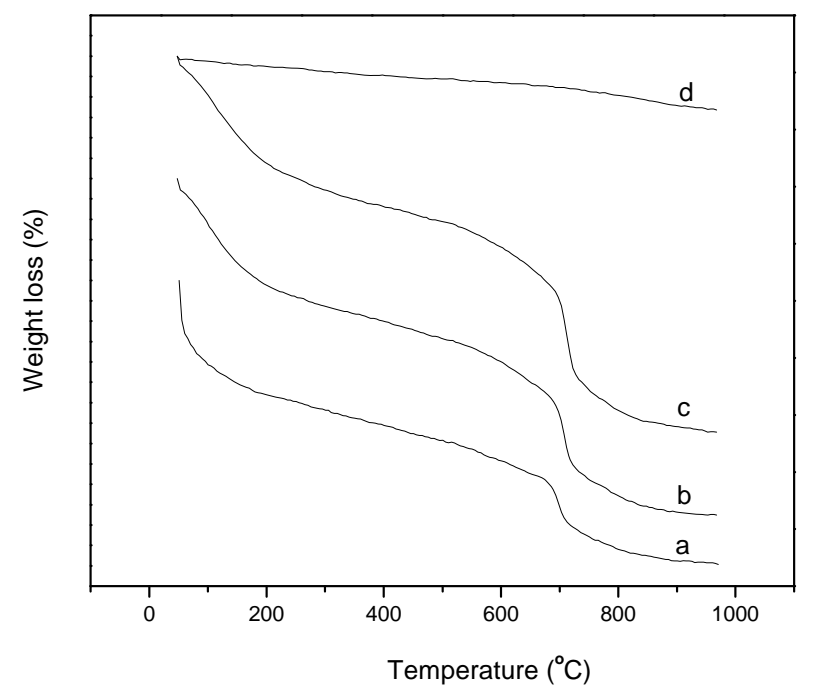

Figure 5. TGA curves for a: 40 wt $\%$ ZS/HMS; b: 50 wt $\%$ ZS/HMS; c: 60 wt\% ZS/HMS; and d: HMS.

Table 2. Variables and levels for orthogonal test.

\begin{tabular}{ccccc}
\hline Level A (time, h) & $\begin{array}{c}\text { B (Phosphoric } \\
\text { acid, mol/L) }\end{array}$ & C (Acetone, \%) D (solvent, mL) \\
\hline 1 & 8 & 1.0 & 60 & 25 \\
2 & 16 & 1.4 & 70 & 30 \\
3 & 24 & 1.8 & 80 & 35 \\
\hline
\end{tabular}

3. Table 2 is variables and levels for orthogonal test; Table 3 is three factors three levels $\left(\mathrm{L}_{9}\left(3^{4}\right)\right)$ orthogonal experiment and through 9 sets of experiments to determine the optimal conditions for gossypol extraction from cottonseed cake using acetone. The influence of each variable on the extraction yield of gossypol was determined for extraction time (A), phosphoric acid concentration (B), acetone concentration (C), and the amount of solvent (D). From Table 3, it can be seen that the rank order of influence was $\mathrm{A}>\mathrm{C}>\mathrm{D}>\mathrm{B}$. Extracting time had the strongest influence on gossypol extraction, while the phosphoric acid concentration was the least influential variable. The results of range analysis revealed that the optimal combination of these four factors was $\mathrm{A}_{3} \mathrm{~B}_{1} \mathrm{C}_{3} \mathrm{D}_{1}$. The optimum conditions for gossypol extraction from cottonseed cake using acetone were an extraction time of 24 $\mathrm{h}$, phosphate concentration of $1.0 \mathrm{~mol} / \mathrm{L}, 80 \%$ acetone, and solvent dosage of $25 \mathrm{~mL}$. At these optimal values, the average removal rate of gossypol reached $63.75 \%$.

The effects of the ZS/HMS catalyst on gossypol esterification are presented in Figure 6. It is obvious that the conversion of gossypol to acetylated gossypol increased with increasing ZS loading on the catalyst and was as high as $97 \%$ at $50 \mathrm{wt} \%$ ZS loading on HMS. No further increase was observed at high ZS loading on HMS. Again, this high efficiency indicated that the loaded ZS was well dispersed on the HMS surface, thus maximizing catalytic surface area. At ZS loading below $50 \%$, the weaker catalytic activity was due to lower dispersion of $\mathrm{ZS}$ on HMS.

The amount of ZS/HMS catalyst used in the esterification process also affected the acetylated gossypol conversion efficiency. The effect of the catalyst dose on the conversion efficiency is shown in Figure 7. The catalyst amount was varied from $10-70 \mathrm{mg}$ in $10 \mathrm{mg}$ increments. The conversion efficiency of acetylated gossypol increa-

Table 3. The $\mathrm{L}_{9}\left(3^{4}\right)$ orthogonal experiment for determining the optimal conditions for gossypol extraction from cottonseed cake using acetone.

\begin{tabular}{cccccc}
\hline Experiment no. & A & B & C & D & $\begin{array}{c}\text { Extraction of } \\
\text { gossypol (mg/g) }\end{array}$ \\
\hline 1 & 8 & 1.0 & $60 \%$ & 25 & 0.123 \\
3 & 8 & 1.4 & $70 \%$ & 30 & 0.184 \\
4 & 8 & 1.8 & $80 \%$ & 35 & 0.388 \\
5 & 16 & 1.0 & $70 \%$ & 35 & 0.159 \\
6 & 16 & 1.4 & $80 \%$ & 25 & 0.646 \\
7 & 16 & 1.8 & $60 \%$ & 30 & 0.146 \\
8 & 24 & 1.0 & $80 \%$ & 30 & 1.173 \\
9 & 24 & 1.4 & $60 \%$ & 35 & 0.327 \\
K1 & 0.232 & 0.486 & 0.199 & 0.533 & \\
K2 & 0.317 & 0.386 & 0.391 & 0.501 & \\
K3 & 0.777 & 0.455 & 0.736 & 0.291 & \\
R & 0.545 & 0.099 & 0.537 & 0.242 & \\
\hline
\end{tabular}

$\mathrm{K} 1$ : Average extraction of gossypol for the four factors in level 1; K2: Average extraction of gossypol for the four factors in level 2; K3: Average extraction of gossypol for the four factors in level 3; R: mean range. 


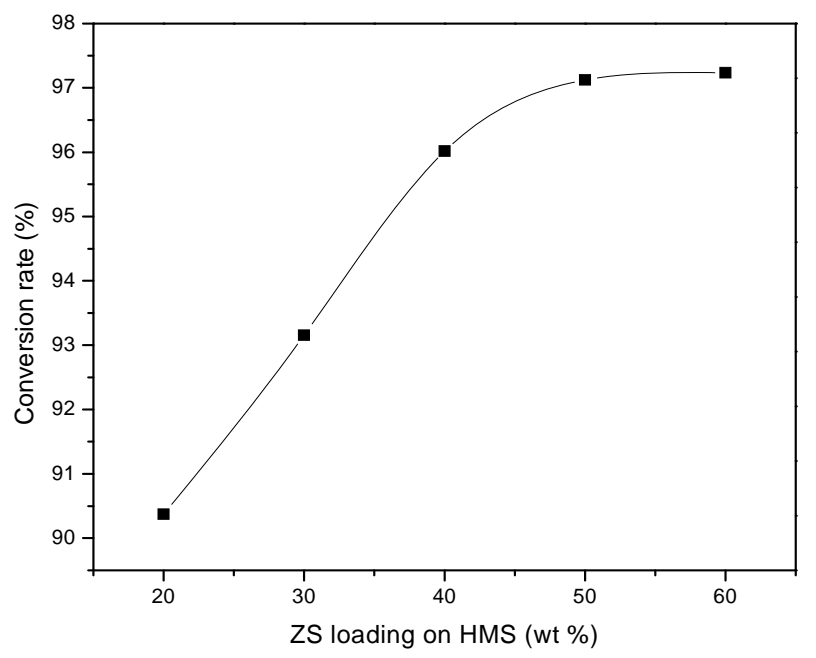

Figure 6. Catalytic activities of solid acid catalysts with different ZS loading on HMS for esterification of gossypol.

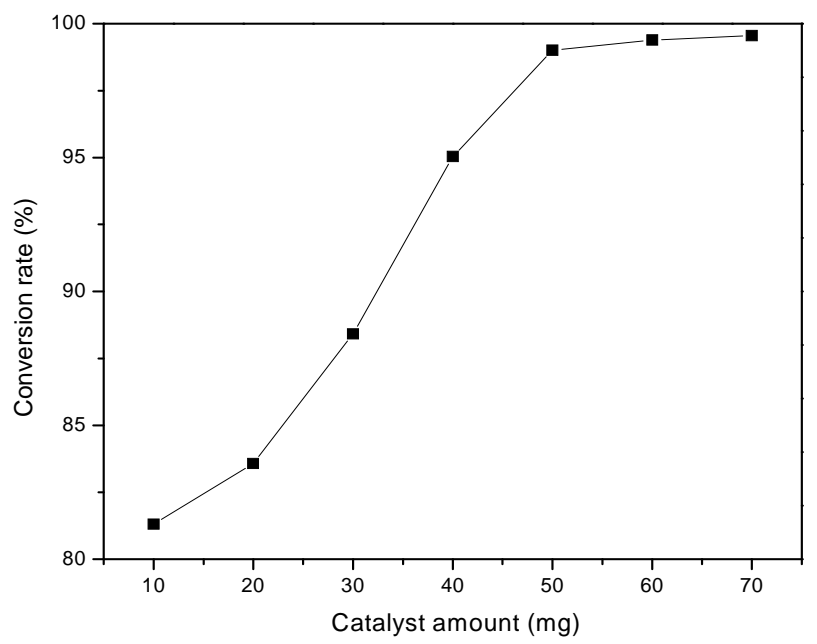

Figure 7. Effect of catalyst amount on the esterification of gossypol.

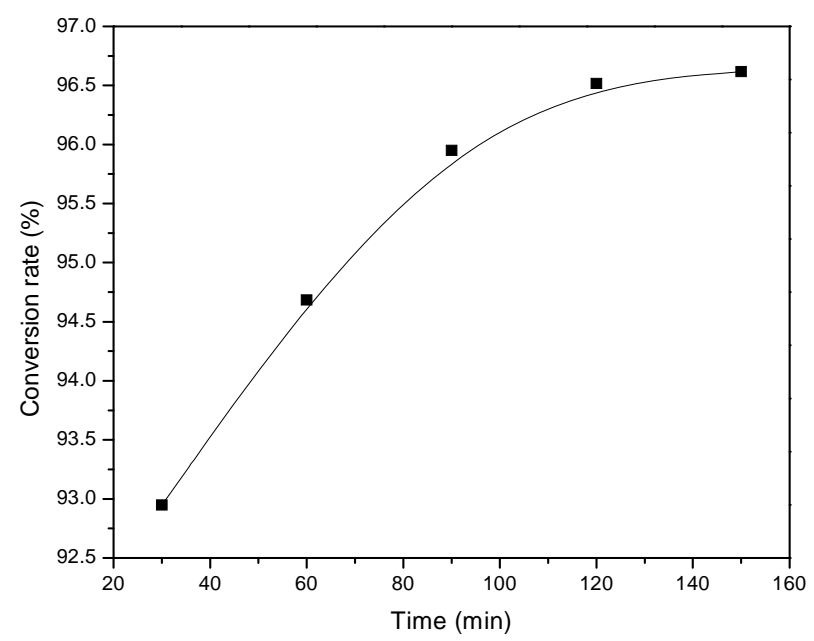

Figure 8. Effect of reaction time on the esterification of gossypol. sed to reach the maximum conversion efficiency at 50 $\mathrm{mg}$ ZS/HMS, while addition of additional catalyst did not significantly increase gossypol esterification efficiency. These results confirmed that the average size of catalyst particle (60 - 80 mesh) was small enough to limit the internal mass transfer inside the catalyst pores.

The reaction was carried out at room temperature with $50 \mathrm{mg} \mathrm{ZS} / \mathrm{HMS}(50 \mathrm{wt} \%$ ) and $2.5 \mathrm{~mL}$ gossypol $(0.6 \mathrm{mg} /$ $\mathrm{mL})$. The mixture was stirred at $200 \mathrm{rpm}$ for $15 \mathrm{~min}$. Then $1.6 \mathrm{~mL}$ distilled $\mathrm{H}_{2} \mathrm{O}$ was added to the solution and it was left standing. Samples were removed every $30 \mathrm{~min}$ to determine gossypol ester production (Figure 8). The conversion rate increased with reaction time and gradually peaked at $120 \mathrm{~min}$. At $120 \mathrm{~min}$, the conversion rate of acetylated gossypol reached $96.5 \%$.

\section{Conclusion}

The synthesized ZS/HMS shows good dispersion by TG, XRD and BET characterizations. The acid activity of the catalysts increases with the increment of the ZS loading. When ZS loading on HMS was 50\%, the optimal amount of catalyst was $50 \mathrm{mg}$ catalyst for an esterification reaction of $120 \mathrm{~min}$, the yield of acetylated gossypol reached up to $96.7 \%$.

\section{Acknowledgements}

The authors would like to acknowledge the support of Doctor's Special Fund of Xinjiang Production and Construction Corps (No. 2010JC13), and Initial Fund for highlevel talents of Shihezi University (RCZX20036).

\section{REFERENCES}

[1] R. D. Stipanovic, D. W. Altman, D. L. Begin, G. A. Greenblatt and J. H. Benedict, "Terpenoid Aldehydes in Upland Cottons: Analysis by Aniline and HPLC Methods," Journal of Agricultural and Food Chemistry, Vol. 36, No. 3, 1988, pp. 509-515. doi:10.1021/jf00081a026

[2] A. A. Nomeir, M. B. Abou-Donia and J. Am, "Photodecomposition of Gossypol by Ultraviolet Irradiation," Journal of the American Oil Chemists Society, Vol. 62, No. 1, 1985, pp. 87-89. doi:10.1007/BF02541497

[3] L. L. Hua, J. J. Zhou and H. Y. Han, "Direct Electrochemiluminescence of CdTe Quantum Dots Based on Room Temperature Ionic Liquid Film and High Sensitivity Sensing of Gossypol," Electrochimica Acta Electron, Vol. 55, No. 3, 2010, pp. 1265-1271. doi:10.1016/i.electacta.2009.10.038

[4] W. A. Pons, J. Pominski, W. H. King, J. A. Harris and T. H. Hopper, "Recovery of Gossypol from Cottonseed Gums," Journal of the American Oil Chemists Society, Vol. 36, No. 8, 1959, pp. 328-332. doi:10.1007/BF02640046

[5] R. D. Stipanovic, J. C. Donovan, A. A. Bell and F. W. Martin, "Factors Interfering in Gossypol Analysis of Okra and Glandless Cottonseed Using Direct Aniline Extrac- 
tion," Journal of Agricultural and Food Chemistry, Vol. 32, No. 4, 1984, pp. 809-810. doi:10.1021/jf00124a027

[6] W. A. Pons, R. A. Pittman and C. L. Hoffpauir, "3-Amino1-propanol as a Complexing agent in the Determination of Total Gossypol," Journal of the American Oil Chemists Society, Vol. 35, No. 2, 1958, pp. 93-97. doi:10.1007/BF02672661

[7] S. Furuta, H. Matsuhashi and K. Arata, "Catalytic Action of Sulfated Tin Oxide for Etherification and Esterification in Comparison with Sulfated Zirconia," Applied Catalysis A: General, Vol. 269, No. 2, 2004, pp. 187-191. doi:10.1016/j.apcata.2004.04.017

[8] J. C. Juan, J. C. Zhang, Y. J. Jiang, W. L. Cao and M. A. Yarmo, "Zirconium Sulfate Supported on Activated Carbon as Catalyst for Esterification of Oleic Acid by n-Butanol under Solvent-Free Conditions," Catalysis Letters, Vol. 117, No. 3-4, 2007, pp. 153-158. doi:10.1007/s10562-007-9128-3

[9] J. R. Sohn and D. H. Seo, "Preparation of New Solid Superacid Catalyst, Zirconium Sulfate Supported on $\gamma$-Alumina and Activity for Acid Catalysis," Catalysis Today, Vol. 87, No. 1-4, 2003, pp. 219-226. doi:10.1016/j.cattod.2003.09.010

[10] C. L. Chen, T. Li, S. Cheng, H. P. Lin, C. J. Bhongale and C. Y. Mou, "Direct Impregnation Method for Preparing Sulfated Zirconia Supported on Mesoporous Silica," Microporous and Mesoporous Materials, Vol. 50, No. 2-3, 2001, pp. 201-208. doi:10.1016/S1387-1811(01)00453-X

[11] J. C. Juan, Y. Jiang, X. J. Meng, W. L. Cao, M. A. Yarmo and H. C. Zhang, "Supported Zirconium Sulfate on Carbon Nanotubes as Water-Tolerant Solid Acid Catalyst," Materials Research Bulletin, Vol. 42, No. 7, 2007, pp. 1278-1285. doi:10.1016/j.materresbull.2006.10.017

[12] C. L. Chen, S. Cheng, H. P. Lin, S. T. Wong and C. Y. Mou, "Sulfated Zirconia Catalyst Supported on MCM-41 Mesoporous Molecular Sieve," Applied Catalysis A: General, Vol. 215, No. 1-2, 2001, pp. 21-30.

\section{doi:10.1016/S0926-860X(01)00504-X}

[13] T. R. Pauly and T. J. Pinnavaia, "Pore Size Modification of Mesoporous HMS Molecular Sieve Silicas with Wormhole Framework Structures," Chemistry of Materials, Vol. 13, No. 3, 2001, pp. 987-993. doi:10.1021/cm000762t

[14] J. C. Juan, J. C. Zhang and M. A. Yarmo, "Study of Catalysts Comprising Zirconium Sulfate Supported on a Mesoporous Molecular Sieve HMS Foresterification of Fatty Acids under Solvent-Free Condition," Applied Catalysis A: General, Vol. 347, No. 2, 2008, pp. 133-141. doi:10.1016/j.apcata.2008.06.004

[15] P. T. Tanev and T. J. Pinnavaia, "A Neutral Templating Route to Mesoporous Molecular Sieves," Science, Vol. 267, No. 5199, 1995, pp. 865-867. doi:10.1126/science.267.5199.865

[16] S. M. Rlseman, F. E. Massoth, G. M. Dhar and E. M. Eyring, "Fourier Transform Infrared Photoacoustic Spectroscopy of Pyridine Adsorbed on Silica-Alumina and $\gamma$ Alumina," The Journal of Chemical Physics, Vol. 86, No. 10, 1982, pp.1760-1763.

[17] L. Forni, "Comparison of the Methods for the Determination of Surface Acidity of Solid Catalysts," Catalysis Reviews-Science and Engineering, Vol. 8, No. 1, 1974, pp. 65-115. doi:10.1080/01614947408071857

[18] G. D. Yadav and A. D. Murkute, "Preparation of the Novel Mesoporous Solid Acid Catalyst UDCaT-4 via Synergism of Persulfated Alumina and Zirconia into Hexagonal Mesoporous Silica for Alkylation Reactions," Advanced Synthesis and Catalysis, Vol. 346, No. 4, 2004, pp. 389-394. doi:10.1002/adsc.200303212

[19] D. P. Quintanilla, A. Sánchez, I. Hierro, M. Fajardo and I. Sierra, "Functionalized HMS Mesoporous Silica as Solid Phase Extractant for $\mathrm{Pb}(\mathrm{II})$ Prior to Its Determination by Flame Atomic Absorption Spectrometry," Journal of Separation Science, Vol. 30, No. 10, 2007, pp. 1556-1567. doi: $10.1002 /$ jssc. 200600540 